\title{
Statement by the OEGGG with Review of the Literature on the Mode of Delivery of Premature Infants at the Limit of Viability
}

\section{Stellungnahme der OEGGG mit Literaturübersicht zum Geburts- modus von Frühgeborenen an der Grenze der Lebensfähigkeit}

\section{()(1) (요 $\odot$}

\author{
Authors \\ and Obstetrics (OEGGG) \\ Affiliations \\ 1 Universitätsklinik für Frauenheilkunde und Geburtshilfe \\ der Paracelsus Medizinischen Universität Salzburg, \\ Salzburg, Austria \\ 2 Frauenklinik des Klinikums Klagenfurt, Klagenfurt \\ am Wörthersee, Austria \\ 3 Universitätsklinik für Frauenheilkunde und Geburtshilfe, \\ Medizinische Universität Graz, Graz, Austria \\ 4 Medizinische Universität Wien, Universitätsklinik \\ für Frauenheilkunde, Vienna, Austria
}

Thorsten Fischer ${ }^{1}$, Manfred Mört| ${ }^{2}$, Philipp Reif ${ }^{3}$, Herbert Kiss ${ }^{4}$, Uwe Lang ${ }^{3}$, for the Austrian Society for Gynaecology

Key words

mode of delivery, early preterm birth, pregnancy, perinatal mortality, neonatal morbidity

\section{Schlüsselwörter}

Geburtsmodus, frühe Frühgeburtlichkeit, Schwangerschaft, perinatale Mortalität, neonatale Morbidität

$$
\begin{array}{ll}
\text { received } & 16.5 .2018 \\
\text { revised } & 2.8 .2018 \\
\text { accepted } & 3.8 .2018
\end{array}
$$

Bibliography

DOI https://doi.org/10.1055/a-0669-1480

Geburtsh Frauenheilk 2018; 78: 1212-1216 @ Georg Thieme Verlag KG Stuttgart · New York | ISSN 0016-5751

\section{Correspondence}

Univ.-Prof. Dr. med. Thorsten Fischer

Universitätsklinik für Frauenheilkunde und Geburtshilfe der Paracelsus Medizinischen Universität Salzburg Müllner Hauptstraße 48, 5020 Salzburg, Austria th.fischer@salk.at

$\circledast$ Deutsche Version unter: https://doi.org/10.1055/a-0669-1480

\section{ABSTRACT}

In 2017, the Austrian Society for Paediatric and Adolescent Medicine (ÖGKJ) published a guideline on the primary care of premature infants at the limit of viability. In this guideline, it is recommended that a Caesarean section be preferred as mode of delivery with regard to an early preterm birth $(22+0$ $24+6$ weeks of pregnancy) due to an allegedly lower perinatal risk of cerebral haemorrhage. In contrast to this, the Austrian Society for Gynaecology and Obstetrics (OEGGG) considers there to be no clinical and scientific basis for this recommendation and the mode of delivery in the case of early preterm birth must be adapted to the individual maternal and foetal clinical situation. The international data available from the generally retrospective investigations show heterogeneous results regarding the mode of delivery. The prospective and randomised data in this regard are insufficient. A Cochrane analysis does not show any advantage in favour of a Caesarean delivery. The German-language guidelines (AWMF and Switzerland) make analogous recommendations for adapting the mode of delivery with regard to an early preterm birth individually to the respective clinical situation. In the case of an early preterm birth and a singleton in cephalic presentation, the OEGGG therefore recommends individual management of the delivery which takes the maternal and foetal clinical situation into account and also includes vaginal delivery as a mode of delivery in the clinical decision process.

\section{ZUSAMMENFASSUNG}

Im Jahr 2017 hat die Österreichische Gesellschaft für Kinderund Jugendheilkunde (ÖGKJ) eine Leitlinie zur Erstversorgung von Frühgeborenen an der Grenze der Lebensfähigkeit veröffentlicht. In dieser Leitlinie wurde empfohlen, im Bereich der frühen Frühgeburt $(22+0-24+6$ SSW $)$ aufgrund eines vermeintlich geringeren perinatalen Hirnblutungsrisikos als Entbindungsmodus eine Sectio caesarea zu präferieren. Im Gegensatz dazu ist die Österreichische Gesellschaft für Gynäkologie und Geburtshilfe (OEGGG) der Ansicht, dass es für diese Empfehlung keine klinische und wissenschaftliche Grundlage gibt und der Entbindungsmodus im Bereich der 
frühen Frühgeburtlichkeit der individuellen maternalen und fetalen klinischen Situation angepasst werden muss. Die internationale Datenlage der meist retrospektiven Untersuchungen zeigt heterogene Ergebnisse zu der Fragestellung des Entbindungsmodus. Prospektive und randomisierte Daten liegen nur unzureichend vor. Eine Cochrane-Analyse zeigt keinen Vorteil zugunsten der Schnittentbindung. Die deutschsprachigen Leitlinien (AWMF und Schweiz) kommen zu analogen Empfehlungen, den Entbindungsmodus im Bereich der frühen Frühgeburt individuell der jeweiligen klinischen Situation anzupassen. Die OEGGG empfiehlt deshalb im Bereich der frühen Frühgeburtlichkeit bei Einlingen in Schädellage ein individuelles Entbindungsmanagement, das die maternale und fetale klinische Situation berücksichtigt und auch eine Vaginalgeburt als Geburtsmodus in den klinischen Entscheidungsprozess einschließt.

\section{Background}

In 2017, the neonatology and paediatric intensive care working groups of the Austrian Society of Paediatric and Adolescent Medicine (ÖGKJ) and ethics in paediatric and adolescent medicine of the ÖGKJ as well as the Institute for Ethics and Law in Medicine of the University of Vienna (IERM) published a guideline on "Primary care of premature infants at the limit of viability" in the monthly journal Kinderheilkunde [Paediatrics] [1].

This "guideline" analyses - from a paediatric viewpoint - the legal, ethical, organisational and prognostic aspects of early preterm infants born between $22+0$ and $24+6$ WOP (weeks of pregnancy). In the "guideline", recommendations on the mode of delivery during these early weeks of pregnancy are made for the first time. A brief statement based on selected publications summed up that a planned Caesarean section versus a vaginal delivery in the collective of early premature infants led to a lower risk of cerebral haemorrhage in the premature infants and should thus be preferred.

This unilateral recommendation on the mode of delivery which was not agreed upon with the OEGGG - particularly in the form of increased liability with implied legally binding effect as a "guideline" should be rejected in the OEGGG's view, since it technically relates to the core competence of another field, obstetrics, and is not technically tenable. The "guideline" takes relevant medical aspects of obstetrics into account and the international studies available are not given appropriate consideration. A guideline report on the "Primary care of premature infants at the limit of viability" "guideline" [1] was not published.

The problematic statement to be discussed in the paediatric guideline reads as follows:

"The data available suggest that, in the case of an extremely preterm birth, a Caesarean section performed by experienced obstetricians, even with a cephalic presentation, offers an advantage with regard to mortality and morbidity of the child. It can also be shown that premature births at the start or end of the day as well as on Sundays and holidays and especially at night are associated with a poorer outcome than premature births during core working hours. In the case of a premature birth at the limit of viability which is very likely foreseeable, a "planned" Caesarean delivery therefore appears to be an advantage for the child."

Specialist representatives of the Austrian Society for Gynaecology and Obstetrics were not consulted on this obstetric recommendation while it was being drafted. There is no consensus with representatives of the Austrian Society for Perinatal Medicine; disagreements were not published.
Following an extensive discussion and evaluation of the available literature, the following compromise proposal was unanimously adopted as a binding replacement for the previously published paragraph 6.4 of the paediatric "guideline" by the representatives of the paediatric and gynaecological association:

"There are inherently very little randomized data on the optimal mode of delivery at the limit of viability and the results of published studies are contradictory. Individual studies appear to suggest an advantage regarding mortality and the rate of cerebral haemorrhage through a Caesarean delivery, while others do not find any difference. Ultimately, the optimal mode of delivery must be individually determined."

\section{Additional Information from the OEGGG with a Review of the Literature}

When compared to other European countries, the rate of premature birth in Austria - 7.7\% [2] - is in the middle. In particular, extremely preterm infants prior to the end of the 26th WOP are still at risk of morbidity and mortality associated with a premature birth. The international data on this topic are heterogeneous and insufficient. There are no detailed obstetrical and neonatal data on the mode of delivery for the gestational age of $22+0$ to $24+6$ WOP discussed in the guideline.

The criticism of the representatives of the OEGGG relates to two points in particular:

1. The recommended mode of delivery in the case of early preterm infants and

2. The clinical procedure in the case of deliveries outside of core working hours.

Our statement of the OEGGG refers exclusively to preterm singleton births with a cephalic presentation. Multiple births and births with a breech presentation are exempted below due to the varying data and thus differing recommendations.

\section{Method}

The obstetrical recommendations of the published paediatric "guideline" were unanimously rejected by the executive board of the OEGGG after taking note of them. Thus at the request of the OEGGG, there was a specialist meeting on 23 May 2017 with representatives of the three societies ÖGKJ, IERM and OEGGG with the objective of changing, within the consensus of professional societies, the recommendation which pertains to the mode of delivery with regard to early premature birth and which is problem- 
atic from a legal standpoint and incorrect from a medical standpoint. Participants were: A. Berger (Vienna), C. Dadak (Vienna), T. Fischer (Salzburg), U. Kiechl-Kohlendorfer (Innsbruck), H. Kiss (Vienna), U. Lang (Graz), M. Mörtl (Klagenfurt), P. Reif (Graz), H. Salzer (Tulln) and M. Wald (Salzburg). The recommendation presented by the authors to the executive board of the ÖGGG was discussed twice in the executive board and unanimously approved by the executive board of the ÖGGG on 14 March 2018 for submission for publication.

To answer the questions (mode of delivery in early premature birth and influence of the time of delivery on neonatal morbidity), a literature search was conducted in PubMed (literature up to 03/ 2018 taken into account) and the literature relevant for answering the question was considered.

\section{Mode of Delivery in Early Preterm Birth}

The currently valid AWMF guideline [3], which was created with the cooperation of neonatal intensive care physicians and representatives of the German Society for Gynaecology and Obstetrics, as well as representatives of the German Society for Perinatal Medicine, recognised the insufficient and, to some extent, contradictory data on the mode of delivery in the case of preterm birth and therefore words a recommendation in an open way: "The results of available studies on the mode of delivery are contradictory. Whether a Caesarean delivery offers advantages in a specific case must be individually assessed, taking the condition and the child into account".

The valid Swiss recommendations which have not been revised since 2011 come to an analogous conclusion [4]. A Swiss publication therefore does not recommend a general Caesarean section in situations of early preterm birth unless it is proven that the rate of Caesarean sections, which is proven to be increasing, also leads to a neurological benefit for the premature infants. The Swiss guideline focuses in particular on early premature infants with a cephalic presentation without any associated maternal or foetal risks in whom a primary Caesarean section offers no advantage [4]. By contrast, the perinatal mortality in early preterm births is decreased through Caesarean section in the case of a twin pregnancy or breech presentation. Children with weight retardation would benefit from a Caesarean delivery up to $30+0$ WOP.

The collective of pregnant women at risk of a very early preterm delivery is very heterogeneous. Prenatal indications are pitted against maternal indications. Therapy-refractory birth events (such as therapy-refractory contractions, amniotic sac prolapse, amniotic infection syndrome, premature placental abruption) are pitted against iatrogenic pregnancy terminations (such as particularly severe preeclampsia, partial placental abruption, severe placental insufficiency). This clinical variability which leads to early preterm delivery does not permit or permits only a limited retrospective neonatal analysis of the morbidity associated with the birth. Premature infants susceptible to developing cerebral haemorrhage are more frequently children with a concomitant neonatal infection and frequently the result of the maternal infection. Experience shows that these children are regularly delivered vaginally due to the mechanics of the birth or events occurring in the short term. Preterm infants following severe placental insuffi- ciency or maternal preeclampsia are almost exclusively delivered via a primary Caesarean section since medicinal cervical ripening is not possible for reasons of time or uterine contractions are not tolerated by the generally growth-retarded foetuses. The bias of the heterogeneous indications for delivery is, to date, a nearly unsolvable problem in answering the question of the optimal mode of delivery in the case of early preterm birth. A Caesarean delivery in the case of an advanced birth, for example, due to a amniotic sac prolapse or therapy-refractory contractions, can have a negative effect on the individual neonatal morbidity risk due to the severe and sometimes traumatic child development.

Prospective randomised studies are desirable. The only Cochrane analysis on this topic, dating from 2013, identified only 4 studies which meet the strict Cochrane criteria [5]. The authors of the Cochrane Review conclude that the data from the 122 cases analysed are not sufficient to be able to derive recommendations on the mode of delivery. All four studies were discontinued early due to recruitment difficulties. There were no differences between the delivery groups (planned Caesarean section vs. planned vaginal delivery) in terms of the important neonatal mortality and morbidity criteria (asphyxia, perinatal death, hypoxic ischaemic encephalopathy, respiratory distress syndrome and postnatal development). The rate of acute maternal complications was significantly higher in the randomised Caesarean section group (7) 122 events) versus the vaginal delivery group (wound infections, deep leg vein thrombosis, toxic shock and sepsis). Because of the difficult surrounding ethical circumstances in a very heterogeneous clinical collective, other prospective studies are not expected or only expected to a limited degree. The neonatal and maternal long-term consequences of unnecessary Caesarean sections, where applicable, were inherently not reviewed in this setting, however they are well known and described.

Three retrospective studies from 2010, 2013 and 2016 [6-8] conclude that early preterm infants would not (automatically) benefit from a Caesarean section:

- "In our all-corners cohort, replicative of everyday obstetric practice, caesarean delivery did not improve neonatal outcomes in preterm infants". (23+0-36 + 0 WOP) [6].

- "In severely premature infants born after spontaneous onset of labour, the risk of adverse perinatal outcome does not seem to depend upon the mode of delivery, whereas the risk of maternal complications is significantly increased after caesarean section". $(25+0-32+6$ WOP $)[7]$.

- "In the preterm cohort, cesarean delivery was not protective against poor outcomes and in fact was associated with increased risk of respiratory distress and low Apgar score compared with vaginal delivery". (24 + 0-34 + 0 WOP) [8].

However, these retrospective studies in a clinically heterogeneous collective are limited in their evidence and frequently arrive at contradictory results. Ghi et al. [7] demonstrate an increased tendency to develop intraventricular haemorrhage (OR: 1.7) in the group of children born vaginally versus children born via Caesarean section. Antenatal administration of steroids was, however, significantly more rare in the vaginal group, at $67.7 \%$, versus a rate of $88.0 \%$ in the Caesarean section group. Werner et al. [8] did not find any difference in the case of cerebral haemorrhage, 
- Table 1 Delivery methods (vaginal delivery vs. Caesarean section) in birth year 2016 in Austria (only live births; 17).

\begin{tabular}{|l|r|r|}
\hline WOP & \multicolumn{2}{|c|}{ Type of delivery } \\
& Vag. delivery & \multicolumn{1}{|c|}{ Caesarean section } \\
\hline Up to $22+6$ & $65(100.0 \%)$ & \\
\hline $23+0$ to $25+6$ & $45(31.9 \%)$ & $96(68.1 \%)$ \\
\hline $26+0$ to $28+6$ & $42(18.2 \%)$ & $189(81.8 \%)$ \\
\hline $29+0$ and above & $60186(70.7 \%)$ & $24925(29.3 \%)$ \\
\hline Total & $60338(70.5 \%)$ & $25210(29.5 \%)$ \\
\hline
\end{tabular}

however, a difference in the case of respiratory distress syndromes to the disadvantage of the Caesarean section group (39.2 vs. 25.6\%; OR 1.74). Small numbers of cases, very heterogeneous antenatal treatments to encourage lung development, heterogeneous indications for delivery and the mixing of the analysis of early and less early preterm births permit only limited conclusions regarding the mode of delivery on neonatal morbidity and mortality.

In a comprehensive review, Berger et al. [9] conducted a morbidity and mortality analysis of preterm infants depending on the mode of delivery. Studies which show a reduction in neonatal mortality in the case of early preterm birth $[10,11]$ are facing studies which do not show any difference [12-15]. However, these studies investigate in part collectives with paediatric birth weights up to $1500 \mathrm{~g}$ and not children with a gestational age of $22+0$ to $24+6$ WOP in an isolated manner.

These studies are also only of limited importance for answering the present question, since they primarily investigated neonatal mortality and the preterm infants came from collectives which are clinically very different.

In a current American study from 2017 [16], a large preterm birth collective was likewise retrospectively analysed. However, the study design is carefully selected, since in this study, the collectives "primary Caesarean section" vs. "planned vaginal delivery" were investigated and thus realistically reflect the hospital collectives. The secondary Caesarean sections were also included in the group of planned vaginal deliveries. In the collective of planned vaginal deliveries, no increased rate of neonatal cerebral haemorrhage (IVH grade 3 or 4) was detected. Overall, the children of the "vaginal delivery group" even tended to have a better outcome.

In the opinion of the representatives of the Austrian Society of Gynaecology and Obstetrics, the optimal mode of delivery in the case of early preterm birth must be determined depending on the overall foetal and maternal situation. In more than two thirds of cases (68.1\%), a primary or secondary Caesarean delivery was performed in 2016 in Austria in the case of early preterm delivery $(23+0-25+6$ WOP, only live births). This Caesarean section rate is stable. Over a nine-year period (2008-2016) the Caesarean section rate in the collective of early preterm births was $66.8 \%$ on average. In the nine-year average, $33.3 \%$ of the early preterm
- Table 2 Delivery methods (vaginal delivery vs. Caesarean section on average) in birth years 2008-2016 in Austria (only live births; 17).

\begin{tabular}{|l|r|c|}
\hline \multirow{2}{*}{ WOP } & \multicolumn{2}{|c|}{ Type of delivery } \\
& \multicolumn{1}{|c|}{ Vag. delivery } & \multicolumn{1}{c|}{ Caesarean section } \\
\hline Up to $22+6$ & $389(98.2 \%)$ & $7(1.8 \%)$ \\
\hline $23+0$ to $25+6$ & $358(33.2 \%)$ & $720(66.8 \%)$ \\
\hline $26+0$ to $28+6$ & $316(15.5 \%)$ & $1722(84.5 \%)$ \\
\hline $29+0$ and above & $496440(71.4 \%)$ & $198895(28.6 \%)$ \\
\hline Total & $497503(71.2 \%)$ & $201344(28.8 \%)$ \\
\hline
\end{tabular}

births (live births) were still delivered vaginally (2016: 31.9\%) $(\vee$ Tables 1 and 2) [17].

Clinical experience shows that, in the case of associated maternal complications such as severe preeclampsia and eclampsia, which frequently occur in combination with severe placental insufficiency, there is often no leeway with regard to time or the clinical situation for a vaginal delivery. The collective of potential vaginal deliveries in the case of early preterm delivery is seen above all in the case of therapy-refractory contractions and/or an amniotic sac prolapse. There is a consensus among obstetricians that a quick vaginal delivery with a cephalic presentation versus Caesarean delivery may sometimes be more gentle in these cases. Mothers in this situation and, consequently, their children are affected by concomitant vaginal infections far more frequently. In particular, foetal infections associated with the early preterm delivery worsen the neonatal prognosis, especially the risk of intraventricular haemorrhage, and thus in this collective, neonatal morbidity associated with the infection but independent of the mode of delivery can be expected. The higher rate of over $30 \%$ vaginal deliveries at an early gestational age between $23+0$ to $25+6$ WOP and the consecutive decrease in vaginal deliveries to approximately $18 \%$ at a later gestational age between $26+0$ to $28+6$ WOP [17] reflects, in our opinion, the clinical situation of predominantly therapy-refractory contractions at a very low gestational age and the need for indicated pregnancy terminations due to placental insufficiency and maternal indications at a higher gestational age ( $\triangleright$ Tab. 1 and 2 ). Subsequently $(>29+0$ WOP) the rate of vaginal deliveries increases in Austria in the case of preterm birth to $70.7 \%$.

\section{Influence of the Time of Delivery on Neonatal Morbidity}

The "guideline" of the paediatric societies cites publications [1820] which are intended to show a "worse outcome" of premature infants born outside of core working hours. The times of an unfavourable outcome are defined as the start and end of the day, Sundays and holidays and all nights. This would mean that, out of 168 weekly hours, a lower-quality provision of healthcare is encountered for at least 128 hours in perinatal centres of the highest level. The guideline therefore calls for a preventive and thus pre- 
ferred Caesarean section delivery in the cases in which a "preterm delivery is very likely foreseeable". In the opinion of the representatives of the OEGGG, a provision of healthcare of the highest quality should be continuously guaranteed in perinatal centres, independent of the time and day of the week. Increased neonatal mortality for weekend working hours cannot be proven [21], however, it can have influencing factors which are centre-dependent and thus in need of correction in individual cases. The advice that a delivery is should be favoured in the case of a "high likelihood of delivery" can be misleadingly interpreted and it leads to the avoidable risk of early iatrogenic preterm birth. In borderline situations, in the case of very early preterm birth, the delivery can be "brought forward" by hours in situations in which it is virtually certain that birth is imminent, whereby in individual cases, an even better provision of paediatric healthcare could be guaranteed. The persons responsible for the Cochrane analysis created for this purpose phrase the concerns of the OEGGG regarding this topic analogously and unambiguously: "There is therefore, a real possibility that a policy of planned caesarean section may increase the number of babies born preterm".

\section{Conclusions and Outcome for Practice}

The discussion about the debated paediatric "guideline" and the present statement from the OEGGG show that there is a need for an interdisciplinary guideline for the diagnosis, prediction, prevention, treatment and neonatal primary care in the case of preterm birth. The publication of the AWMF-S3 guideline "Caesarean section" is still expected this year. The representatives of the OEGGG do not find it helpful when statements from outside the field which have an apparently medically and legally binding nature on a suggestive "guideline level" regarding the clinical approach are made in our field. This statement from the OEGGG is intended to facilitate critical reflection on the obstetrical approach and ensure forensic certainty for our colleagues in obstetrics.

\section{Acknowledgements}

We thank Mr. Hermann Leitner from the Austrian Register of Births, Institute for Clinical Epidemiology of the Tirol Hospitals for providing data from the Austrian Register of Births.

\section{Conflict of Interest}

The authors declare that they have no conflict of interest.

\section{References}

[1] Berger A, Kiechl-Kohlendorfer U, Berger J et al. Erstversorgung von Frühgeborenen an der Grenze der Lebensfähigkeit. Monatschr Kinderheilk 2017; 2: 139-147

[2] Statistik Austria. Lebendgeborene (mit inländischem Geburtsort) nach ausgewählten medizinischen Merkmalen seit 2006: Schwangerschaftsdauer (in Wochen und Tagen). 2017. Online: https://www.statistik.at/ web_de/statistiken/menschen_und_gesellschaft/bevoelkerung/ geborene/medizinische_und_sozialmedizinische_merkmale/110619. html; last access: 11.09 .2018

[3] Arbeitsgemeinschaft der Wissenschaftlichen Medizinischen Fachgesellschaften (AWMF). S2k-Leitlinie: Frühgeborene an der Grenze der Lebensfähigkeit. AWMF-Leitlinien-Register Nr. 024-019. 2017. Online: http:// www.awmf.org/uploads/tx_szleitlinien/024-019l_S2k_Fr\%C3\%BCh geburt_Grenze_Lebensf\%C3\%A4higkeit_2014-09-verlaengert.pdf; last access: 11.09 .2018

[4] Berger TM, Bernet V, El Alama S et al. Perinatal care at the limit of viability between 22 and 26 completed weeks of gestation in Switzerland. 2011 revision of the Swiss recommendations. Swiss Med Wkly 2011; 141: w13280

[5] Alfirevic Z, Milan S], Livio S. Caesarean section versus vaginal delivery for preterm birth in singletons. Cochrane Database Syst Rev 2013; (9): CD000078

[6] Racusin DA, Antony KM, Haase J et al. Mode of delivery in premature neonates: does it matter? Am J Perinatol Rep 2016; 6: e251-e259

[7] Ghi T, Maroni E, Arcangeli T et al. Mode of delivery in the preterm gestation and maternal and neonatal outcome. J Matern Fetal Neonatal Med 2010; 23: 1424-1428

[8] Werner EF, Han CS, Savitz DA et al. Health outcomes for vaginal compared with cesarean delivery of appropriately grown preterm neonates. Obstet Gynecol 2013; 121: 1195-1200

[9] Berger R, Papadopoulos G, Maul H. Entbindungsweg bei Frühgeburt. Frauenarzt 2016; 57: 748-753

[10] Malloy MH. Impact of cesarean section on neonatal mortality rates among very preterm infants in the United States, 2000-2003. Pediatrics 2008; 122: 285-292

[11] Muhuri PK, Macdorman MF, Menacker F. Method of delivery and neonatal mortality among very low birth weight infants in the United States. Matern Child Health J 2006; 10: 47-53

[12] Wylie BJ, Davidson LL, Batra M et al. Method of delivery and neonatal outcome in very low-birthweight vertex-presenting fetuses. Am J Obstet Gynecol 2008; 198: 640.e1-640.e7

[13] Riskin A, Riskin-Mashiah S, Lusky A et al.; Israel Neonatal Network. The relationship between delivery mode and mortality in very low birthweight singleton vertex-presenting infants. BJOG 2004; 111: 1365-1371

[14] Durie DE, Sciscione AC, Hoffman MK et al. Mode of delivery and outcomes in very low-birth-weight infants in the vertex presentation. Am J Perinatol 2011; 28: 195-200

[15] Reddy UM, Zhang J, Sun L et al. Neonatal mortality by attempted route of delivery in early preterm birth. Am J Obstet Gynecol 2012; 207: 117. e1-117.e8

[16] Kuper SG, Sievert RA, Steele R et al. Maternal and Neonatal Outcomes in Indicated Preterm Births Based on the Intended Mode of Delivery. Obstet Gynecol 2017; 130: 1143-1151

[17] Leitner H; Fachbeirat des Geburtenregisters Österreich. Geburtenregister Österreich. Bericht über die Geburtshilfe in Österreich 2016. 2017. Online: https://www.iet.at/data.cfm?vpath=publikationen210/groe/ groe-jahresbericht-2016; last access: 11.09.2018

[18] Heller G, Schnell R, Misselwitz B et al. Why are babies born at night at increased risk of early neonatal mortality?. Z Geburtshilfe Neonatol 2003; 207: 137-142

[19] Stephansson O, Dickman PW, Johansson AL et al. Time of birth and risk of intrapartum and early neonatal death. Epidemiology 2003; 14: 218222

[20] Gould JB, Qin C, Chavez G. Time of birth and the risk of neonatal death. Obstet Gynecol 2005; 106: 352-358

[21] Gould JB, Qin C, Marks AR et al. Neonatal mortality in weekend vs. weekly births. JAMA 2003; 289: 2958-2962 